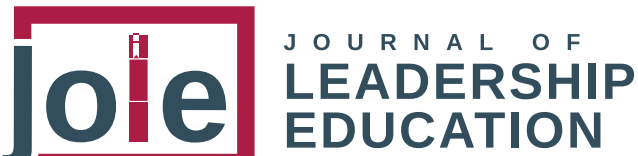

Kyle L. Bower Kathleen D. Kelsey

Impact Evaluation Unit University of Georgia
Nicholas E. Fuhrman

Agricultural Leadership,

Education and

Communication

University of Georgia
Lauren Ledbetter Griffeth

College of Agricultural \&

Environmental Sciences University of Georgia

OCTOBER 2021

RESEARCH SECTION

\title{
GENERATIVE LEADERSHIP DEVELOPMENT IN AN AGRICULTURAL LEADERSHIP PROGRAM
}

\section{Abstract}

Adult agricultural leadership programs (ALP) train people to address the needs of a diversifying society with pressing social, economic, environmental, and political challenges. Additionally, these programs offer transformative learning experiences that lead to a greater capacity of current and prospective leaders to become change agents in their communities. In a profession where vitality, strength, and perseverance are fundamental, the agricultural industry needs leaders who remain aware of the foundational knowledge contributed by their predecessors. At the same time, it also necessitates innovation that may revolutionize the agricultural industry for decades to come. In this mixed-method study, we asked participants of a state-based ALP to complete the Loyola Generativity Scale $(\mathrm{N}=48)$ that measures generative concern, with higher scores indicating stronger generative concern. Survey results $(\mathrm{N}=48)$ indicated average overall generative concern. However, there was a considerable variation among participants, scores ranging from 45 to 77 . To understand the range of attitudes, we conducted interviews $(\mathrm{N}=11)$ with ALP participants. Generativity Theory provided the foundation of our qualitative analysis. We identified how participants are acting generatively in their leadership roles by promoting the sustainability of agriculture through social engagement, capitalizing on opportunities for teaching and learning, and expanding social capital through intergenerational professional networks. From this research, scholars and practitioners will gain a more nuanced understanding of how this ALP is facilitating generative leadership among today's leaders so they may continue transforming their industry by connecting generational cohorts through the transmission of experience, knowledge, and expertise.

\section{Introduction}

Leadership development encourages individuals to create a vision, think strategically, demonstrate competency in areas of expertise, and motivate others through interpersonal communication and emotional intelligence (Roupnel et al., 2019). However, in a continually transforming society, it is also essential to acknowledge the collaborative nature of leadership development. While leadership skills reside within the individual, leadership development forms through reciprocal interactions with others (Roupnel et al., 2019; Cullen-Lester et al., 2017) and within the context of shifting social norms and expectations (Montgomery, 2020; Roupnel et al., 2019).

To become an effective leader, Hackman and Johnson (2013) encourage individuals to explore their leadership identity by knowing who you are, how you act, what you do, and how you work with others. Leaders become impactful when they engage others in personal development, as an effective leader relies on their ability to listen for creative opportunities to 
integrate others' personal goals and professional expertise with their own (Macaux, 2012; Montgomery, 2020). Research indicates that connecting individuals through leadership development does not only yield positive leadership skills, it also creates a leadership culture that fosters innovation, equity, and inclusion (Macaux, 2012; Montgomery, 2020; Roupnel et al., 2019). Socializing leaders to become aware of their social responsibility of upholding current personal and organizational values, while also creating space for sustainability and innovation, is imperative to fostering the next generation of leaders. Furthermore, leadership that is generative in nature calls for recognizing the value in others and even placing others' goals ahead of one's own (Macaux, 2012).

Through adult leadership development programs, current and future leaders learn how to expand their impact through a continual process of coaching, mentoring, and active learning that supports the goal of fostering complex interactions between individuals and their social and organizational environments (Roupnel et al., 2019). Furthermore, these programs offer professionals the opportunity to assess their strengths and weaknesses in a way that encourages collaboration (Roupnel et al., 2019). For instance, adult agricultural leadership programs (ALP) address the needs of a diversifying society with pressing social, economic, environmental, and political challenges regarding the United States (U.S.) agricultural industry (Bush et al., 2019). Individuals in these programs engage in transformative learning experiences that lead to a greater capacity to become change agents and industry advocates (Bush et al., 2019) and develop a deeper sense of self-awareness. Additionally, ALP participants report having positive relationships with family and peers as a result of joining these programs and benefit from mentoring relationships (Lamm et al., 2017). However, little is known about how these programs contribute to generative leadership development following participation.

The research reported here focuses on the professional experiences of individuals who participated in a land-grant university sponsored ALP, Advancing Georgia's Leaders in Agriculture and
Forestry (AGL). The purpose was to better understand how AGL promoted interpersonal relations across age cohorts. We explored how the program encouraged a sense of connectedness among agricultural leaders to broaden the intellectual knowledge that spans generations within the agricultural sector, specifically focusing on the concept of generativity (Erikson, 1963). We surveyed participants' generative concern and conducted interviews to explore generativity within the context of agricultural leadership. Our findings resulting from this mixed-methods analysis contribute to the existing literature by advancing the conversation regarding the need for greater reciprocity in such programs. Furthermore, we identified how participants acted generatively in their leadership roles by promoting sustainable agricultural practices, capitalizing on teaching and learning opportunities, and expanding social capital through intergenerational professional networks. From this research, scholars and practitioners will gain a more nuanced understanding of how today's leaders transform their industry by becoming increasingly self-aware of meaningful connections between generational cohorts that engage the generative transmission of experience, knowledge, and expertise.

\section{Literature Review}

\section{Generativity and Leadership Development}

Generativity is a psychosocial stage of development that prepares adults for understanding themselves, their contributions to the world around them, and the lasting impact they have on their communities after they are gone (Erikson, 1963). The process of developing generativity includes forming an awareness of generative concern (overall concern for future generations), generative goals (desired accomplishments in daily life), and generative actions (behaviors indicative of generativity) (Kotre, 1984, 2004; McAdams \& de St. Aubin, 1992; McAdams \& Logan, 2004). Furthermore, the meaning-making that develops throughout the life course occurs 
within cultural contexts (Kotre, 1984) and is motived by an intrinsic desire as well as a cultural demand (Ehlman \& Ligon, 2012). Therefore, to understand one's generative contribution, it's important to first understand who the individual once was (e.g., one's identity as an early-career professional) and who they have become (e.g., their identity as experienced leaders) (Bower et al., 2019; Kotre, 1984; McAdams \& Logan, 2004).

The concept of generativity has evolved over time, and given the socially constructed aspects, it is important to acknowledge the various ways individuals can be generative. According to Kotre (1984), there are four types of generativity: biological, parental, technical, and cultural. The first two refer to the ability and willingness to directly nurture a future generation (i.e., bearing and raising children). Technical and cultural types of generativity refer to sharing transferable skills, knowledge, and beliefs that represent the self (i.e., a craft, an art form, industry specific knowledge). However, technical and cultural types of generativity are distinct from one another regarding their purpose. For instance, Kotre (1984) explained that generativity is considered technical when a teacher demonstrates a skill (e.g., the "how to") so less experienced individuals can gain knowledge that will impact their futurity. A generative transfer becomes cultural when the teacher not only shares or demonstrates the skill but also passes on the contextual meaning of the skill to those in their circle of influence.

In relationship to leadership development, generative leadership is a combination of both technical and cultural generativity in that it promotes the continuous progression of high performance, organizational adaptation, and innovation within individuals performing as leaders in their industry (Lane \& Maxfield, 1996; Surie \& Hazy, 2006). Generativity aids the transfer of industry knowledge and business practices, and it challenges leaders to improve their judgment, contributing to organizational sustainability, promotes continuity, and adaptive change (Macaux, 2012; Slater, 2003). Furthermore, leaders who demonstrate a sense of generative concern are likely to be inclusive of others' ideas and skills in achieving organizational goals, and they recognize the value of collaboration to provide lasting contributions to society (Slater, 2003).

In the context of the agricultural industry, generative leadership is particularly relevant in situations of complexity when uncertainty and rapid change are dominant. Because outcomes are not certain, the focus of leadership development should be on the process of managing change (Macaux, 2012; Surie \& Hazy, 2006). The most effective leaders understand that change is inevitable and work towards creating connections within the industry to foster change (Cullen-Lester et al., 2017).

Agricultural leadership development programs such as AGL offer participants a variety of experiences that cultivate network growth, such as site visits to different agricultural industry operations, team building activities, and how to identify leadership opportunities within their respective employment settings (Kaufman \& Carter, 2005). As the agricultural industry continues to change, there is a need to educate individuals on the value of collective leadership styles as predecessors possess indispensable industry experience and those entering the workforce to carry the potential to transform the industry for greater sustainability. Including generativity in ALPS will help to educate current agricultural leaders on the importance of balancing traditional organizational structure with modern ideas positioned to address continuous economic and cultural change (Imada, 2004).

\section{Background of the Study}

\section{Advancing Georgia's Leaders in Agriculture and Forestry (AGL)}

The agricultural industry needs leaders who remain aware of the foundational knowledge that is contributed from their predecessors while also being innovative and open to new ideas that may help to improve the agricultural industry over time. Agriculturalists and forestry professionals are not only charged with being technical experts in production practices, they must also act as policy advocates and business professionals. ALPs aim to educate, empower, and connect emerging leaders 
in agriculture, forestry, and natural resources to be dynamic industry professionals.

To be chosen for the AGL program, applicants must be nominated by leaders in the industry and then participate in an interview to become a part of the 25-person cohort. Participants are encouraged to problem-solve across disciplines and industries through active learning on site tours, networking, and participating in leadership development activities ranging from personality assessments to personal growth projects.

\section{Subjectivity Statements}

Similar to those participating in the AGL program, we represent diverse specializations. Dr. Bower is a qualitative researcher whose research focuses on the generative experiences during middle and later life. Through a critically informed perspective, her work contributes to the understanding of generative connectedness that spans age cohorts. Dr. Kelsey is an evaluation specialist who focuses on measuring the impact of adult education programs. Dr. Fuhrman specializes in quantitative methodology and researches best education practices in the nonformal learning environment. Dr. Ledbetter Griffeth is the Administrative Director of the AGL program and has worked with the program for several years. She continues to research leadership development in the agricultural sector.

\section{Conceptual Framework}

\section{Generativity Theory}

Although understood widely as a psychosocial construct occurring throughout adult development, generativity also provides a lens to explore the "intergenerational transmission of that which is valued" (de St. Aubin et al, 2004, p. 266). Generativity scholars suggest that in order to understand what people value and why, we must first understand who they were and who they have become over time (Kotre, 1984; McAdams \& Logan, 2004). Cultural generativity closely examines sociohistorical factors that influence individuals throughout their lives as life experiences influence generative outlets (Kotre, 1984, 1996; Rubinstein et al., 2015). For instance, Rubinstein et al. (2015) expanded on the idea of cultural generativity, adding what they term as "dividuality" (p. 548), or the bi-directional connectedness between self and others. The authors maintained that the inner desire to act generatively was influenced by others, with others referring to individuals or the social environments in which adults developed their identity.

\section{Methods}

\section{Research Design}

To better understand the generative leadership development of AGL participants, the lead author collected both quantitative and qualitative data for this study. This mixed methods approach improved the credibility and utility of the findings as data were collected from participants actively engaged with AGL (Greene et al., 1989; Guest, 2013). While the quantitative data provided information regarding the generative concern of participants using an established scale, qualitative data aimed to explore how participants acted generatively in their leadership roles. Therefore, we used a sequential mixed method design to first identify generative individuals based on survey score, and then we interviewed AGL participants so we could more comprehensively understand generative concern among this sample of agricultural leaders (Creswell \& Clark, 2011; Mertens, 2017).

\section{Loyola Generativity Scale (LGS)}

The Loyola Generativity Scale (LGS) (McAdams \& de St. Aubin, 1992) was used to measure generative concern. No changes were made to the original 20item instrument, however, we added six demographic questions to the end of the survey for a total of 27 questions. Demographic items included respondent's sex, age, race, geographic region, industry with which they most closely identified as working within, and highest education level completed. These contextual items were used to further examine the LGS data for trends based on the demographic characteristics of 
the respondent. Alpha was set a priori at 0.05 for all tests of significance.

The LGS is comprised of 20 items which together measure one's generative concern. Possible scores can range from a low of 20 to a maximum of 80 and each item is presented with response options ranging from 1 (the statement never applies to the respondent) to 4 (the statement very often applies to the respondent). Tests of content validity and construct reliability in previous studies have found the LGS to work well following a reverse coding of six items (McAdams et al., 1998; McAdams \& de St. Aubin, 1992), and this study found that the 20 items were reliable (Cronbach's $a=0.842$ ). An item analysis revealed that eliminating any one item from the construct would not significantly improve the ability of the construct to detect one's generative concern, and all 20 items were retained.

AGL participants $(N=75)$, both past and present, were eligible to participate in the study. The survey was administered through Qualtrics and participants were given two weeks to respond. Two reminder emails were sent out resulting in a $64 \%(n=48)$ response rate. A post hoc reliability analysis was conducted to determine consistency with which respondents scored themselves and to ensure that the instrument worked as intended. The instrument remained reliable.

\section{Participant Interviews}

The interview protocol consisted of an amended version of the Foley Center (2009) guided autobiography. Some prompts, such as describing an "adolescent event" and a "childhood event," were removed to focus the conversation more on career development; however, participants were permitted to use personal examples when they felt it appropriate as we recognize personal and professional development often overlaps. Participants were invited to first describe their current position and any career background information they felt was important to the conversation. They were then asked to describe a high point, low point, and turning point in their career trajectory. Next, they were asked to describe a moment when they faced a moral dilemma, how they reconciled the situation, and in what ways this impacted their leadership development. The interview concluded with their reflections of short-term and long-term personal and professional goals.

Interviews began after survey data were collected. Interview participants were selected using purposive sampling to identify a core sample to ensure data were collected from individuals who were actively engaged with AGL in some capacity (e.g., current participant, mentor, board member, engaged alumni). Dr. Ledbetter Griffeth, having the most knowledge of the population, recommended nine individuals who completed the survey, of which five volunteered to be interviewed. Dr. Bower conducted all the interviews and relied on snowball sampling to identify additional participants for a total of 11 participants.

Interviews lasted approximately an hour with the shortest interview being 30 minutes and the longest being one hour and 20 minutes. All interviews were conducted via Zoom, an online conferencing platform due to Covid-19 social distancing requirements.

\section{Data Analysis}

\section{Quantitative Data}

SPSS version 26 was used to analyze all numeric data. We ran descriptive analyses for sex, race, geographic region, work sector, and education level are reported descriptively. Means for the overall LGS score as well as means for each of the 20 items are reported in Table 1. An independent samples t-test was used to explore the potential for significant differences based on gender. 


\section{Table 1}

Summary of Responses to Items Comprising the Loyola Generativity Scale (LGS)

\section{LGS Item}

I try to pass along the knowledge I have gained through my experiences.

I feel that other people need me.

I think I would like the work of a teacher.

I feel as though I have made a difference to many people.

I volunteer to work for a charity.

I have made/created things that have had an impact on other people.

I try to be creative in most things that I do.

I think that I will be remembered for a long time after I die.

I believe society should be responsible for providing food and shelter for all homeless people.

Others would say that I have made unique contributions to society.

If I were unable to have children of my own, I would like to adopt children.

I have important skills that I try to teach others.

I feel that I have done things that will survive after I die.

In general, my actions have a positive effect on other people.

I feel as though I have done things of worth to contribute to others.

I have made many commitments to many different kinds of people, groups, and activities in my life.

Other people say that I am a very productive person.

I have a responsibility to improve the neighborhood in which I live.

People come to me for advice.

I feel as though my contributions will exist after I die.
Mean (SD)

$3.56(0.50)$

$3.15(0.51)$

$2.31(0.85)$

$2.83(0.69)$

$3.08(0.92)$

$2.98(0.81)$

$3.10(0.75)$

$2.33(0.81)$

$2.85(0.77)$

$2.29(0.71)$

$2.73(1.11)$

$2.98(0.70)$

$3.35(0.70)$

$3.54(0.54)$

$3.71(0.50)$

$3.31(0.66)$

$3.42(0.54)$

$3.08(0.71)$

$3.15(0.62)$

$2.81(0.70)$

Note. Response scale ranged from 1 = "The statement never applies to me" to 4 = "The statement applies to me very often or nearly always." 


\section{Qualitative Data}

Interview data were analyzed using ATLAS.ti 8 for Mac. Preliminary coding consisted of mostly structural and descriptive codes (Saldaña, 2015). However, as we collected more data we identified process codes, which conveyed action (Saldaña, 2015). As our coding structure became more saturated, we then sorted like codes into code groups, which helped to conceptually organize the data in a meaningful way. Codes and code groups were operationalized using the commenting feature provided by ATLAS.ti 8 for Mac. This is an essential step while engaging in iterative data analysis (Friese, 2019). Each code began with a definition grounded in literature, however, as the analysis evolved, so did the definition of specific codes. The coding framework in Table 2 presents select codes from our codebook in ATLAS.ti.

\section{Table 2}

\section{Coding structure}

Code Group

Cultural Generativity

Ag Culture

Ag Culture: being female

Technical Generativity

Generative Leadership

Code teaching learning
Comment (Definition of code or code group)

Creating, renovating \& conserving the skillset to be passed on to successors (Kotre, 1984)

Social descriptions of agriculture, farming, ranching, or allied sector

Social descriptions of agriculture, farming, ranching, or allied sector within the context of being female

Teaching skills to successors or passing on the skillset in which the skills are embedded. (Kotre, 1984)

Impacting others: Situations, events, or experiences that demonstrate teaching a skill to promote the professional development of others

Impacting others: Situations, events, or experiences that demonstrate learning about oneself to promote the professional development of self as to become a better leader of others

Leadership development that meets the needs of the present without compromising the ability of future generations to meet their own needs (Macaux, 2012)

Building Establishing sustainable relationships that span relationships career development

Creativity Inventive solutions to existing problems, also acknowledges the flexibility of the industry to allow new ideas

Innovation
Solutions that fill current needs and fosters the ability of future generations to meet their own needs (The World Commission on Environment and Development, 1987) 


\section{Findings}

To determine the extent of generativity practiced among the AGL participants, we present the findings within the context of how participants acted. The qualitative findingsare organized into three prominent themes: promoting a sustainable agriculture, capitalizing on opportunities for teaching and learning, and building and maintaining relationships. Together, the quantitative and qualitative data provide a comprehensive representation of generative concern among agricultural leaders who participated in AGL.

\section{Quantitative Results}

A total of participants completed the instrument for a $64 \%$ response rate. Twenty-four males and 24 females responded, and the average respondent age was 38 years $(S D=7.81)$. The majority of the sample identified as White $(n=47,98 \%)$ and one respondent identified as Black or African American. The majority of the sample (57.5\%) indicated residing in a rural geographic region of Georgia followed by a suburban (31.9\%) and urban (8.5\%) geographic region, respectively. One respondent indicating residing in a Coastal region of Georgia. The majority of respondents worked in the agriculture or forestry sector (70.3\%), followed by government (19.1\%) and the allied sector (electric cooperative, trucking, etc.) (10.6\%), respectively. Most respondents held a fouryear $(41.7 \%)$ or professional degree $(52.1 \%)$, followed by some college $(4.2 \%)$ or a high school diploma (2.1\%).

Descriptive statistics were used to summarize responses to each of the 20 items before examining the overall LGS score across respondents (Table 1). Six items were modified slightly to contain positive wording (e.g., from "not have" to "have") so that the interpretation of the response scale would be consistent across the original scale.

The LGS data revealed several interesting trends (Table 1). Regardless of respondent demographic characteristics, the overall mean LGS score was $60.58(S D=7.21)$ for the construct of 20 items (scale ranged from 20 to 80 ). Further analysis of the overall mean LGS score based on respondent characteristics revealed several findings relevant for interpreting the outcomes of the AGL program experience. Comparing the items by respondent sex showed no statistically significant difference between males (Mean item score $=2.29$ ) and females (Mean item score $=2.33$ ). Differences in overall LGS scores were also not statistically significant between males and females at the $a=0.05$ level (Table 3 ).

\section{Table 3}

Comparison of Mean LGS Scores Between Male and Female Respondents

\begin{tabular}{lll}
\hline Respondent Sex & \# of Respondents & Mean LGS Score (SD) \\
\hline Male & 24 & $58.67(6.84)$ \\
Female & 24 & $62.50(7.20)$ \\
\hline
\end{tabular}

Note. LGS scores could range from a minimum of 20 to a maximum of 80 .

The overall LGS score was also not significantly associated with respondent age. Although the strength of the association between age and LGS score was not significant, the direction of the association was positive, implying that older respondents were more likely to have higher LGS scores than younger respondents.

\section{Qualitative Findings}

The qualitative findings provided further insight into how participants were acting generatively in their leadership positions. In particular, we found that the agricultural leaders, whose voices are represented in the findings and who were given pseudonyms 
to protect their privacy, discovered ways to promote connectedness and inclusion, sought to educate themselves and others, and demonstrated the importance of building and maintaining relationships. In describing the findings, we begin with the cultural aspects of agriculture that focus on the connectedness within the industry and the field's potential to become more inclusive as agriculture diversifies. Next, we present generative actions, such as teaching and learning, that participants expressed to be professionally impactful. Finally, we discuss the perceived importance of building and maintaining relationships to contribute to the sustainability of leadership in agriculture.

\section{Promoting a Sustainable Agriculture}

Connectedness of Agriculture. The AGL program has a reputation of bringing people together from all agricultural sectors, which participants perceive as a benefit of the program. The program builds on a collaborative environment that is characteristic of the agricultural industry. Fiona described the industry by saying, "Well, until COVID, we joke that we didn't shake hands, we hugged necks in agriculture," referring to the family-like environment.

At every stage of career development and spanning ages, all the participants noted how meaningful their nomination to the program was to their professional and personal development. Once in the program, participants continued to make connections throughout the agricultural community. Participants described how AGL improved their access to people in existing leadership positions by scheduling visits to governmental offices (local, state, and national) and inviting speakers who held leadership positions to engage with AGL cohorts. For instance, while in the program and just embarking on her career, Fiona was introduced to several influential people in her region, one of whom advised her to keep asking questions and learning from those already established. He made time to answer her questions, and now as a leader in her field, she makes the time for others. Fiona said:

When I go and talk to AGL students and hand them my business card and say, 'This is my cell phone number. Call me at any time.' That makes me feel, it's kind of self-serving because it makes me feel really good, but I feel like it's also good for them because they have access to the people with more experience. I think that's very strong in agriculture.

Several others contributed similar comments, explaining how their careers were influenced by the strong support of others in their networks.

Another example of how AGL embodied the connectedness of agriculture was the nomination process for applicants. To participate, individuals were nominated by someone who perceived them to be an influential future leader, thereby enhancing the self-confidence and assurance of applicants. For instance, Jacky reflected on being nominated, saying:

Then the second week of January, I ended up with an email that said I had been nominated by AGL. And I was really excited 'cause that was several months ago. I didn't think he would remember and be serious about it, but it made me feel great. It was very humbling just to be nominated because he thought enough of me professionally to nominate me for that program.

Participants also shared how they used their leadership capstone project (a requirement of the program) to bring people in the community together. For instance, Ben explained he manages an agritourism venue. Throughout his career he observed detriments of farm succession firsthand. This inspired his leadership capstone project whereby he planned to create (i.e., build, fund, and manage) an interactive museum to educate children about agriculture. He said:

For a long time have felt that there's a tremendous disconnect. My kid's generation, ag, they have no idea where their food comes from. No clue. If you go in my daughter's fourth grade class and say, 'Raise your hand if somebody in your family has a farm,' now granted, we live in a rural county, but if you go and ask that, you have two hands go up, and this could be one person with a chicken house and one person with a Christmas tree 
farm. Nobody knows where each fruits and vegetables come from.

Ben believed developing a children's museum would lessen the cultural divide between rural- urban communities by cultivating young adults' curiosity regarding agriculture and providing exposure to food sources. Through opportunities such as the capstone project, other participants also sought to develop resources that connected younger generations with agriculture, farming, and forestry so they could develop a deeper appreciation of sustainable agriculture in the U.S.

Potential for Inclusion. Although the agricultural industry was perceived as welcoming, participants also described instances of less inclusive environments. Lack of inclusion was more apparent among female participants. Several women shared experiences during their career when they felt undervalued, not supported, and in the most severe instances, blatantly disrespected based on their gender. Participants directly addressed gender discrimination by acknowledging the "male-centric" industry and the effects on their leadership styles. Although several women shared negative experiences, those situations did not deter them from their career goals; rather, they used those experiences to become more effective leaders. Hannah shared an instance where she felt unheard. Because of that situation, she reported becoming a more empathetic leader. Hannah said:

I didn't find my voice was heard [in previous job], and so I took that away as, when there comes a time when I manage people, I will always listen. Because that was very difficult, when I felt like my requests were going unheard and unanswered. And so, in any time that's what I look for in leaders. Even if you're going to disagree or something else you can do, at least being that ear to listen and try to get to some kind of resolution, even if it's not what the person.

Female participants expressed a desire to help their younger counterparts to become successful. Gaby recalled a hiring meeting during which older women questioned the female applicant's ability to do the job because she was newly married and within childbearing age. Gaby said:

I just, I looked over at them and I said, 'It's not her job to figure that out, it's [the company's] job to figure it out. If they want her and she wants to have a baby, it's their role to figure out how to keep her,' and they kind of were like 'Yeah.' I don't know why it's been put on the female to think, 'Are you going to accommodate me?' I feel like the people in charge should say, 'We respect you and appreciate the job you do so much, this is what we're willing to do ensure you're comfortable, and that you're willing to transition back.' I'm not sure where that language or barrier has happened.

Gaby went on to explain how situations such as this influenced her desire to help young women enter the agricultural industry. Several other participants mirrored her sentiments and shared ideas about improving upon weaknesses in agriculture to better serve the diversifying workforce that supports it. Al said, "At the end of the day, we hope we leave whatever we do a little bit better than the how we found it." His statement resonates throughout the interviews as all participants acknowledged there are constantly ways to improve the connectedness of leadership within agriculture and forestry through effective teaching and learning.

\section{Capitalizing on Opportunities for Teaching and Learning}

Teaching. This sub-theme pertains to the teaching of life skills in addition to industry skills. Dawn described how she taught skills to a younger employee who recently graduated high school. She helped him develop the skills needed to be successful throughout his career, such as problem solving and time management. She explained, "And simple things like when you shake someone's hand, when they come speak to you, please stand up. You need to stand up, you cannot shake their hand sitting down." Ben 
also expressed the importance he places on teaching his employees life skills by stating, "Thirty percent of my staff is brand new every year, so that's that many opportunities to go and teach people skills, you know, life skills, soft skills that they'll take with them and become teachers, or nurses, or whatever they do next."

Fiona was also in a position to train young employees and interns: "I'm interested in having, even not student workers, but having direct reports. And understanding that their success ends with me, and I have to build them up to build the whole industry up." Participants explained that through these experiences, they learned a lot about themselves as leaders and AGL encouraged them to recognize other opportunities in their sector to mentor or teach in a way that strengthens the industry.

Learning. While they were engaged in the generative activity of teaching others, participants also shared how they continued to learn about themselves. The leadership program provided the opportunity for participants to take several validated personality tests. The majority of participants explained how integral this activity was for their continued leadership development. For instance, Ben said, "Just to help me understand who I am, and why I'm that way, and what to do with it." Hannah also reflected on the importance of self-assessment in becoming a leader by stating:

It was not only presented as these are your strengths, but here's where you might fall and have trouble and here's how to correct those. That I really took to heart, because I felt that it was my job to participate and grow from it, and part of that was taking what I learned on those tests, and how to find those areas that are my weaknesses and not dwell on them and get upset with them, but use them as growth opportunities.

The AGL program provided a safe space where participants could identify their strengths and weaknesses in a manner that benefitted their leadership style. Carol said, "First of all, you can never stop learning, never, ever. If you do, you have just given up." Fiona shared similar sentiments by stating:
And I don't want to ever think that I know everything, I'm a lifelong learner. So, I'm always asking and I'm always wanting to be involved in the process. But, of being a recipient of that for 12 years now. I'm trying to be more mindful, incorporating the younger people, and taking the time to explain to them and bring them into the process. I think because I was such a beneficiary of that it makes me want pass down.

AGL facilitated leadership development by giving participants the ability to identify their strengths and weakness, and even more importantly, engage in an ongoing learning process of self-development, which is directly in line with generative thinking.

\section{Building and Maintaining Relationships}

Each participant acknowledged how AGL helped them to identify creative approaches to fostering a strong sense of community. Additionally, participants accounted for their own past experiences while also inviting new ideas to solve existing and emerging issues. For instance, Isaac used his capstone leadership project to design a mentoring program in his company to address the need for intergenerational transfer of knowledge. He described the intellectual capital being lost as upper management retires. To address this issue, Isaac said:

I thought it was important for them to pass the baton to the next generation. You know, not just from the standpoint of passing knowledge but also from a symbolic ownership perspective. It gives the retiree peace of mind that they're leaving the company, better or as good as they found it, not just leaving. Now I would imagine, as I get closer to the end of my career, I would want to not just walk out the door. You know, the line, folks would feel like they appreciate the ability to pass on the knowledge.

Carol also spoke about the importance of feeling valued from a slightly different perspective as someone who is retired from her first career. She participated in AGL as someone new to agriculture 
and farming; however, she relied on decades of past work experience to inform her AGL leadership capstone project, which aimed to foster a sense of camaraderie among herself and her peers. She felt everyone needed to know they were a valuable part of the team and gifted each person with a "leadership nugget" booklet where they could record meaningful interactions they had with others. She said, "It wasn't really about leadership as much as it was about team." Her gift was meant to inspire her colleagues as she has been inspired throughout her career.

Participants agreed that reciprocity was an important cornerstone to mentoring and building collaborative relationships so that everyone feels valued. A sense of value also allowed others to create and invent their ways of doing things. For instance, Ethan shared how his experience of transitioning to a new job helped form a bond with his successor. Rather than telling her what to do, he recalled, "I shared my thoughts and my opinions. But I also asked, 'What do you want to do? How do you want to see, what is your vision for this? How can I help you?"' To build relationships, Ethan added that trust and openness were essential for the longevity of his career. Ben also explained how relationships developed through AGL continued to contribute to his feelings of reciprocity by stating:

You gotta have those people who feed you, right, and hopefully that's reciprocal [and] you feed each other. So certainly, AGL has been a huge blessing in that regard. I've got a lot of peers that I call on frequently and can bounce ideas off of them, ask questions of them in their area of expertise where maybe my knowledge is there, but more limited than with that being their primary expertise.

Given the cultural changes occurring within the agricultural industry, participants have learned through their own experiences the importance of building and maintaining relationships that span their career. The lessons acquired along the way also played a role in participants' generative contribution in creating space for innovative ideas without discarding foundational knowledge.

\section{Discussion}

The participants represented an essential link in the generative chain of leadership development. In mid-life and mid-career, they acquired experiences that shaped who they are as leaders in agriculture. These men and women are applying what they know in a way that continues the process of generative leadership by sharing their knowledge and wisdom with mentees and direct reports. Our findings, consistent with the literature, suggest generative leaders are well-positioned to share skills necessary to advance their industry and create space for those entering the workforce (Macaux, 2012; Surie \& Hazy, 2006). Furthermore, AGL facilitated a generative leadership style through training opportunities that empowered existing and future leaders. The program aided participants to transfer industry knowledge and business practices to others while challenging them to improve their judgment, innovativeness, organizational sustainability, and adaptability to sustain the industry (Slater, 2003; Surie \& Hazy, 2006).

Participants acknowledged the shifting landscape of agriculture. Whether it was the demographic shift from rural to urban or the sociological shift of including more diversity within leadership positions, participants acknowledged that both types of shifts contributed to their generative concern. While the majority of participants felt a sense of connectedness within the agricultural field, there were instances when participants felt undervalued by their employer. However, when challenges arose, they found a way to reframe the issue into something that created space for more inclusivity. The qualitative findings are aligned with the quantitative survey data. The highest scoring individual item on the LGS instrument related to doing things of worth to contribute to others $(M=3.71)$. Additionally, there was a strong awareness among participants interpreting their actions as having a positive effect on people ( $M=$ 3.54). Our findings suggest that AGL participants perceived the importance of their professional roles to positively influence society around them. Hastings and Sunderman (2019) discussed similar findings, noting that the generative impact on others was a positive predictor of one's ability to create socially responsible change. However, it remains unclear whether AGL participants held such beliefs before entering the program or acquired such skills following 
their participation; thus, more research is needed in this area.

The second theme we identified contextualizes the leadership styles of the participants. All participants found ways to connect to others by sharing knowledge and experience through teachable moments, ranging from formal training to informal guidance. Additionally, they emphasized their ongoing process of learning about themselves and how they were able to interact with others through experiences facilitated by the AGL program. The ability to gain insight from these teachable moments in turn helped them understand how they could be effective leaders in their current position. This finding resonates with generative leadership in that AGL sought to challenge participants to improve their judgment, innovative thinking, and problem-solving skills to strengthen industry sustainability and adaptability (Slater, 2003; Surie \& Hazy, 2006).

While we found various examples of teaching and learning in the qualitative data, results for the survey item, "I think I would like the work of a teacher" were only slightly above average $(M=2.31)$ and accounted for one of the three lowest values among the 20 individual items. While this appears to conflict with the qualitative findings, when considered in the context of this sample, the relationship becomes clearer. These individuals were not teachers, nor were they seeking to be educators. Rather, the teaching they spoke of was more aligned with the first survey item, "I try to pass along the knowledge I have gained through my experiences," ( $M=3.26$ ) which more accurately explains the purpose of teaching and learning.

The final theme demonstrated the importance of networks for growing social and professional opportunities and improving participants' social capital. This finding is also supported by Cullen-Lester et al. (2017), who demonstrated with a conceptual model how network-enhancing leadership development improved leadership capacity of individuals and collectives. Again, the qualitative findings were aligned with the quantitative survey data. Specifically, items about providing advice and having commitments to others all had mean LGS scores above 3.00, implying that respondents believed they did these things "fairly often" and believed in the value of positive, productive relationships.

\section{Conclusions, Future Directions and Limitations}

We asked participants to share their life stories within the context of their careers and from their narratives, we identified themes that characterize their leadership identity from a generativity perspective. In short, the Advancing Georgia's Leaders in Agriculture and Forestry program facilitated participants' generative leadership development by offering them opportunities for professional reflection and growth and engaging participants through activities and events designed to promote connectedness and social capital. Thus, we recommend adult leadership programs (ALP), designed to assist professional leadership development across industries and sectors, initiate self-reflection so individuals can deepen their understanding of their leadership style. For instance, participants of leadership development programs could be prompted to compose a life history narrative in the context of their career trajectory. By composing one's life narrative, individuals are able to self-select experiences, values, and perspectives that have influenced their life in meaningful ways (McAdams \& McLean, 2013; Singer, 2004). Additionally, the meaningful aspects of one's life can then be explored from a leadership standpoint so that individuals are more aware of how their personal strengths and weaknesses can cultivate generative connection between themselves and others. Finally, ALPs can assist with network development to help individuals broaden intellectual ideas that deepen inclusivity within their professional sector, especially when the leader is open to learning new things about their community.

Future research should also concentrate on understanding the generative tendencies of participants before enrolling in ALPs to better examine the role of the program in fostering (or potentially detracting from) one's generative 
development. Identifying specific elements of the ALP that contribute to one's generative tendencies would be valuable when making recommendations for other ALPs promoting generativity among participants.

In a profession where vitality, strength, and perseverance are fundamental, the agricultural industry needs leaders who remain aware of the foundational knowledge contributed by their predecessors. At the same time, it also necessitates innovation that will continue to modernize the industry as technological innovations carry agriculture into the 21 st century. Our aging society generates a novel opportunity to reframe experiences of professional succession and retirement within the agricultural sector as well as beyond. Cultivating the desire of leaders within varying age cohorts to believe in the greater good of one another, in turn, promotes generative awareness, which is tied to positive perceptions of well-being and is important to building sustainable industries (Cheng, 2009). By providing opportunities for leaders to understand their generative concern, ALPs can support participants' willingness to become a part of an industry that is greater than their individual contribution. Furthermore, if adult educators can teach the future leaders how to cultivate generational contributions and link their experiences of intergenerational cohorts, ALPs can empower the next generation of leaders to invest into societal capital that would lead to more robust networks of diverse leaders. 


\section{References}

Bower, K. L., Lewis, D. C., Bermudez, J. M., Singh, A. A. (2021). Narratives of generativity and resilience among LGBT older adults: Leaving positive legacies despite social stigma and collective trauma. Journal of Homosexuality (68)2, 230-251. https://doi.org/10.1080/00918369.2019.1648082

Bush, S. A., Seibel, M. M., Corkins, C. R., \& Elliott-Engel, J. (2019). Evaluating the Virginia Agriculture Leaders Obtaining Results (VALOR) program: Blogs as a reflection process. Journal of Agricultural Education, 60(1), 268-282. https://doi.org/10.5032/jae.2019.01268

Cheng, S. T. (2009). Generativity in later life: Perceived respect from younger generations as a determinant of goal disengagement and psychological well-being. The Journals of Gerontology 64B(1), 45-54. https://doi. org/10.1093/geronb/gbn027

Creswell, J. W., \& Plano-Clark, V. L. (2011). Designing and conducting mixed methods research (2nd ed.). Sage Publications.

Cullen-Lester, K. L., Maupin, C. K., \& Carter, D. R. (2017). Incorporating social networks into leadership development: A conceptual model and evaluation of research and practice. The Leadership Quarterly, 28(1), 130-152. http://dx.doi.org/10.1016/j.leaqua.2016.10.005

de St. Aubin, E., McAdams, D. P., \& Kim, T.-C. (Eds.). (2004). The generative society: Caring for future generations. American Psychological Association. https://doi.org/10.1037/10622-000

Ehlman, K., \& Ligon, M. (2012). The application of a generativity model for older adults. The International Journal of Aging and Human Development, 74(4), 331-344. https://doi.org/10.2190/AG.74.4.d

Erikson, E. H. (1963). Childhood and society (2nd ed.). Norton.

Foley Center for the Study of Lives. (2009). Loyola Generativity Scale. https://www.sesp.northwestern.edu/ foley/instruments/lgs/

Friese, S. (2019). Qualitative data analysis with ATLAS.ti (3rd ed.). Sage Publications.

Greene, J., Caracelli, V., \& Graham, W. (1989). Toward a conceptual framework for mixed-method evaluation design. Educational Evaluation and Policy Analysis, 11(3), 255-274. https://doi. org/10.3102/01623737011003255

Guest, G. (2013). Describing mixed methods research: An alternative to typologies. Journal of Mixed Methods Research, 7(2), 141-151. https://doi.org/10.1177/1558689812461179

Hackman, M. Z., \& Johnson, C. E. (2013). Leadership: A Communication Perspective (6th ed.). Waveland Press.

Hastings, L. J., \& Sunderman, H. M. (2019). Generativity and socially responsible leadership among college student leaders who mentor. Journal of Leadership Education, 18(3), 1-19.

Imada, T. (2004). Generativity as Social Responsibility: The Role of Generations in Societal Continuity and Change. In E. de St. Aubin, D. P. McAdams, \& T.-C. Kim (Eds.), The generative society: Caring for future generations (pp. 83-95). American Psychological Association. https://doi.org/10.1037/10622-006

Kaufman. E. K., \& Carter, H. S. (2005). Agricultural leadership development: From networking to application. Journal of Leadership Education, 4(2), 66-75. https://doi.org/10.12806/V4/I2/AB2 
Kotre, J. (1984). Outliving the self: Generativity and the interpretation of our lives. John Hopkins University Press.

Kotre, J. (1996). Outliving the self: How we live on in future generations. W.W. Norton \& Co.

Kotre, J. (2004). Generativity and culture: What meaning can do. In E. de St. Aubin, D. P. McAdams, \& T.C. Kim (Eds.), The generative society: Caring for future generations (pp. 35-49). American Psychological Association. https://doi.org/10.1037/10622-003

Lane, D., \& Maxfield, R. (1996). Strategy under complexity: Fostering generative relationships. Long Range Planning, 29(2), 215-231. https://doi.org/10.1016/0024-6301(96)00011-8

Lamm, K. W., Sapp, R., \& Lamm, A. J. (2017). The mentoring experience: Leadership development program perspectives. Journal of Agricultural Education, 58(2), 20-34. https://doi.org/10.5032/jae.2017.02020

Macaux, W. P. (2012). Generative leadership: Responding to the call for responsibility. The Journal of Management Development, 31(5), 449-469. https://doi.org/10.1108/02621711211226042

McAdams, D. P., \& de St. Aubin, E. (1992). A theory of generativity and its assessment through self-report, behavioral acts, and narrative themes in autobiography. Journal of Personality and Social Psychology, 62(6), 1003-1015. https://doi.org/10.1037/0022-3514.62.6.1003

McAdams, D. P., Hart, H. M., \& Maruna, S. (1998). The anatomy of generativity. In D. P. McAdams, E. de St. Aubin (Eds.), Generativity and adult development: How and why we care for the next generation, (pp. 7-43). American Psychological Association. https://doi.org/10.1037/10288-001

McAdams, D. P., \& Logan, R. L. (2004). What is generativity? In E. de St. Aubin, D. P. McAdams, \& T.-C. Kim (Eds.), The generative society: Caring for future generations (pp. 15-31). American Psychological Association. https://doi.org/10.1037/10622-002

McAdams, D. P. \& McLean, K. C. (2013). Narrative identity. Current Directions in Psychological Science, 22(3), 233-238. https://doi.org/10.1177/0963721413475622

Mertens, (2017). Mixed methods design in evaluation (Vol. 1). Sage Publications.

Montgomery, B. L. (2020). Academic leadership: Gatekeeping or groundskeeping? The Journal of Values-Based Leadership, 13(2), 1-15. http://dx.doi.org/10.22543/0733.132.1316

Roupnel, S., Rinfre, N., \& Grenier, J. (2019). Leadership development: Three programs that maximize learning over time. Journal of Leadership Education, 18(2), 126-137. https://doi.org/10.12806/V18/I2/T1

Rubinstein, R. L., Girling, L. M., de Medeiros, K., Brazda, M., \& Hannum, S. (2015). Extending the framework of generativity theory through research: A qualitative study. The Gerontologist, 55(4), 548-559. https://doi. org/10.1093/geront/gnu009

Saldaña, J. (2015). The coding manual for qualitative researchers (3rd ed.). Sage Publications.

Singer, J. A. (2004). Narrative identity and meaning making across the adult lifespan: an introduction. Journal of Personality, 72(3), 437-460. https://doi.org/10.1111/j.0022-3506.2004.00268.x

Slater, C. L. (2003). Generativity and stagnation: An elaboration of Erikson's adult stage human development. Journal of Adult Development, 10(1), 53-65. https://doi.org/10.1023/A:1020790820868

Surie, G., \& Hazy, J. K. (2006). Generative leadership: Nurturing innovation in complex systems. Emergence: Complexity and Organization, 8(4), 13-26. 